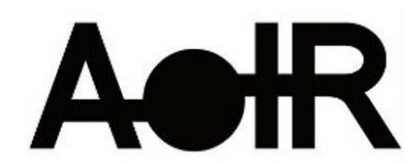

Selected Papers of \#AoIR2021:

The 22nd Annual Conference of the

Association of Internet Researchers

Virtual Event / 13-16 Oct 2021

\title{
DISCOURSES OF VICTIMHOOD AND IDENTITY POLITICS ON SOCIAL MEDIA: UNDERSTANDING AFFECTIVE POLARIZATION DURING THE US ELECTION
}

\author{
Megan Boler \\ University of Toronto \\ Amanda Trigiani \\ University of Toronto
}

This cross-platform digital ethnography examines the nuances of how emotions are expressed and who they are directed towards within social media in order to better understand the phenomenon of affective polarization and the increased emotionality online. By examining how social media users discursively construct representations of self and other through expressions of us/them dichotomies, this project seeks to better understand polarized political identities and how social media users emphasize that their morals and values are similar or distinct from others. How do people on the left and the right feel victimized by the other? What are the moral and emotional injuries as well as the identity politics upon which they base their claims to victimhood? How do social media users rhetorically express their indignation through us/them dichotomizing, to justify their negative affect as well as enactments of revenge as moral duty?

Through examination of the messy and nuanced affect expressed in social media, this project identifies narrative patterns closely linked to ressentiment and "discourses of victimhood". The different stories told by in-groups and out-groups shed light on the affects surrounding moral judgment, influenced by race relations, which distinctively shape affective polarization. Regardless of political stance, expressions of indignation, disgust, and distrust towards the other are supported as a moral stance, creating clear rhetorical distinctions between "us" and "them", influenced by both political and social identities, and placing blame on "them" as the personal and national threat. They are guilty for their immoral, unpatriotic, and violent behaviour. We are righteous, justified, and oppressed. By understanding the existing trends of moral rhetoric, this project reveals how affect is expressed and what broader emotional-moral narratives fuel such affect to deepen our understanding of affective polarization. Our findings explore the similarities and differences in the ways that social media platforms of Facebook, Twitter and Gab construct stories of moral and emotional injuries and narratives of perceived

Suggested Citation (APA): Boler, M. \& Trigiani, A. (2021, October). Discourses of victimhood and identity politics on social media: Understanding affective polarization during the US Election. Paper presented at AolR 2021: The 22nd Annual Conference of the Association of Internet Researchers. Virtual Event: AolR. Retrieved from http://spir.aoir.org. 
victimization towards the guilty other. Such narratives of victimhood unite people based on inner-group pain and polarize based on outer-group blame.

\section{Methodology}

This mixed-methods, three-year project, funded by SSHRC, explores how emotions are expressed in relation to narratives of racial and national belonging within electionrelated social media. Engaging grounded theory (Charmaz 2006), the cross-platform study explores Twitter, Facebook, and Gab in the context of the 2019 Canadian and 2020 U.S. elections. Over the past two years, the PI and a seven person team developed an innovative approach of affective discourse analysis through collaborative and iterative weekly meetings. The four-month digital ethnography conducted in the lead up to and aftermath of each federal election, tracked developing stories and debates within social media conversations across the political spectrum, documented through extensive field notes and findings discussed weekly. We coded a sample of 1800 posts discussing the January 6th Capitol Riots, election fraud, and Black Lives Matter protests using the qualitative data research software Atlas.ti. Contributing an innovative approach to the analysis of affect and emotion within social media, our affective discourse analysis was developed through an intensive iterative process over two years, drawing from critical discourse analysis (Wodak \& Meyer, 2015), rhetorical analysis (Leach, 2000), and "narrative emotions" analysis (Kleres 2011). We engaged grounded theory to develop and refine a codebook suitable for the complex task of coding emotional expression, including: rhetorical and linguistic features; topics to which emotions were directed; and beliefs about in-groups and out-groups.

\section{Theoretical Framework}

For this project, we draw on an emotional-moral framework (Nietzsche) and ressentiment (Brown, 1993) to explore affective polarization in terms of "discourses of victimhood" found across the political spectrum. Analysing social media posts together reveal broader collective narratives that attempt to characterize the victim and the culprit in relation to polarized issues. Ressentiment, or the moralizing revenge of the powerless (Brown, 1993), provides a framework for understanding how social media users moralize the self and demoralize the other while expressing indignation and disgust regarding current political events. Other partisan identities function as a site of blame on which to avenge and redistribute one's pain (Brown, 1993). People often feel "most safe anchored in our subordinated position to avoid addressing our position within dominant groups and to maintain our innocence" (Razack, 1998, p. 132). Both those who are marginalised and historically privileged often make similar identity-based claims to victimization and moral innocence. This project seeks to understand how politicized identities "become attached to its own exclusion" (Brown, 1993, p. 406) and how this influences the proliferation of affective polarization in online political arenas.

Affective polarization "explains the hostility felt by partisans toward members of opposing political parties" (Capuzza, 2018, p. 217). Partisan political identities are reinforced through feelings of interconnectedness, resulting in positive feelings toward ingroup and negative towards the opposition. However, much of the focus of the literature on affective polarization defines in and out group in terms of partisan 
differences, missing the intertwined dynamics of social and racial identities (lyengar et al 2019). While the literature reveals the negative sentiment felt towards the other political group, it simultaneously illuminates a gap in terms of understanding the complex stories that elicit such in-group and out-group affect, and in particular how these polarized narratives are influenced by a history of race relations. This project seeks to better understand polarized political identities and how social media users emphasize that their morals and values are similar or distinct from others.

\section{Contribution}

Moving beyond the binary oppositions of "us/them" that permeates much political communications scholarship, we explore how expressions of identity, solidarity, hate and blame reinscribe collective identities rooted in "victimization", virtues, and perceptions of "others" as perceived threats. We explored the influence of race relations in connection to the moral rhetoric that is used to normalize and rationalize polarized narratives. Specifically, the findings from two years of affective discourse analysis allow us to trace the nuanced complexities of identity politics as shaped by platform politics. Further, the synthesized findings of our coding of 1800 social media posts allows us to paint a complex, grounded, theoretical portrait of identities of victims, enemies, and moral rhetoric that undergirds white supremacy and other discourses of racial and national belonging that have surfaced so explicitly in the U.S. We contribute substantially to the nascent scholarship that seeks to update the concept of ressentiment. Further, our extensive research provides nuanced analyses of the multiple interconnected in and out-group emotions that are expressed in social media related to the Capitol Riots and BLM Protests, thereby radically deepening the concept of affective polarization.

\section{References}

Brown, W. (1993). Wounded attachments. Political Theory, 21(3), 390-410.

Capuzza, J. (2018). 16 Meta-Sexist Discourses and Affective Polarization in the 2016 US Presidential Campaign. Affect, Emotion, and Rhetorical Persuasion in Mass Communication.

Charmaz, K. (2006). Constructing grounded theory: A practical guide through qualitative analysis. Sage.

lyengar, S., Lelkes, Y., Levendusky, M., Malhotra, N., \& Westwood, S. J. (2019). The origins and consequences of affective polarization in the United States. Annual Review of Political Science, 22, 129-146.

Kleres, J. (2011). Emotions and narrative analysis: A methodological approach. Journal for the theory of social behaviour, 41(2), 182-202.

Leach, J. (2000). Rhetorical analysis. Qualitative researching with text, image and sound, 207-226. 
Wodak, R., \& Meyer, M. (Eds.). (2015). Methods of critical discourse studies. Sage. 